\title{
Temperature-dependent sex determination of Ascension Island green turtles
}

\author{
B. J. Godley*, A. C. Broderick, F. Glen, G. C. Hays \\ Marine Turtle Research Group, School of Biological Sciences, Singleton Park, University of Wales, Swansea SA2 8PP, Wales, UK
}

\begin{abstract}
We examined the role played by temperature in the duration of incubation and sex ratio of green turtle hatchlings at Ascension Island, one of the most important green turtle rookeries in the Atlantic. Temperature at control sites at nest depth and in 39 green turtle nests was measured using small temperature recording devices. The sex ratio of hatchlings was ascertained in a sub-sample of monitored nests allowing the description of the relationship between intranest temperature and hatchling sex ratio, demonstrating a pivotal incubation temperature of $28.8^{\circ} \mathrm{C}$. The seasonal profile in sex ratio of hatchlings produced on all nesting beaches at Ascension Island was estimated, showing that a female-biased sex ratio would be expected with a female:male ratio of the order of $3: 1$. The use of nest temperature, air temperature, sand temperature at control sites, and incubation duration as proxies to estimate hatchling sex ratio are discussed.
\end{abstract}

KEY WORDS: Marine turtle $\cdot$ Chelonia mydas $\cdot$ Temperature $\cdot$ Environmental sex determination

\section{INTRODUCTION}

The sex ratio of offspring is a fundamental component of demographic studies. In contrast to other amniote vertebrates, where the phenotypic sex is determined at conception, many reptilian species, including sea turtles, show determination of the sex of the offspring to be dependent on incubation temperature during embryonic development; a process termed Temperature-dependent Sex Determination (TSD) (see Janzen \& Paukstis 1991, Mrosovsky 1994 and Ackerman 1997 for reviews). In marine turtles the temperature experienced during a thermosensitive period, thought to occur during the middle third of incubation, dictates the subsequent sex of the hatchling. Higher temperatures have been shown to produce a greater proportion of females, with cooler temperatures producing more males. The temperature at which an equal sex ratio is produced has been termed the pivotal temperature (Yntema \& Mrosovsky 1980, Miller \& Limpus 1981, Spotila et al. 1987, Mrosovsky \& Pieau 1991).

\footnotetext{
*E-mail:mtn@swan.ac.uk
}

Although the possibility for some degree of inter-population variation in patterns of TSD in at least some sea turtle species exist (Chevalier et al. 1999), pivotal temperatures have been shown to be relatively conservative (Mrosovsky 1994), usually lying close to $29^{\circ} \mathrm{C}$.

TSD has been demonstrated in all marine turtle species: flatback turtles Natator depressus (Hewavisenthi \& Parmenter 2000), Kemp's ridley turtles Lepidochelys kempii (Carrasco et al. 2000), olive ridley turtles Lepidochelys olivacea (McCoy et al. 1983, Wibbels et al. 1998), and hawksbill turtles Eretmochelys imbricata (Mrosovsky et al. 1992, Godfrey et al. 1999, Wibbels et al. 1999). Three species have been more intensely scrutinised: the leatherback turtle Dermochelys coriacea (Mrosovsky et al. 1984, Rimbolt-Baly et al. 1986, Godfrey et al. 1996, Binckly et al. 1998), the loggerhead turtle Caretta caretta (Maxwell et al. 1988, Mrosovsky \& Provancha 1989, 1992, Maloney et al. 1990) and the green turtle Chelonia mydas (Miller \& Limpus 1981, Mrosovsky et al. 1984, Spotila et al. 1987, Godfrey et al. 1996, Godfrey 1997, Kaska et al. 1998, Broderick et al. 2000). A number of population-specific factors have been described as affecting nest temperatures and hence sex ratios of marine turtles. These 
include latitudinal variation, seasonal temperature changes, shading by vegetation, sand colour, episodic events such as rain, and depth of the eggs (Morreale et al. 1982, Mrosovsky et al. 1984, Mrosovsky 1988, Hays et al. 1999).

Ascension Island is unusual in that its beaches are not exposed to shading from vegetation or any other marked 'within-beach spatial variation' in temperature (Broderick et al. 2001). Being a small land mass, Ascension Island experiences no latitudinal variation in temperature, and the prevailing climate means there is very little rain. Consequently, differences in temperatures among nests are mostly a result of 2 major factors: a marked seasonal cycle in temperatures (Hays et al. 1999) and the fact that, although it is small, sand of a wide range of different albedo are found, leading to starkly different thermal regimes in beaches situated very close together (Hays et al. 1995, 1999, 2001a). In addition, the rise in temperature as a result of metabolic heating of embryos has already been described for this site (Broderick et al. 2001), and the temporal and spatial pattern of nesting have already been ascertained with a high resolution (Mortimer \& Carr 1987, Godley et al. 2001a). All of these factors, allied with its remoteness and conservation importance, make this site an excellent location to investigate the sex ratio of hatchling production in this species.

It is important to establish a rigorous methodology for determining hatchling sex ratios in marine turtles, since accurate values for this ratio are an integral step towards understanding the dynamics of populations and the adaptive significance of TSD. The fundamental aim of our study was, therefore, to establish the pivotal temperature for this population and, building upon previous work carried out at the site, to generate an overall estimate of the sex ratio of hatchlings produced within a season.

\section{MATERIALS AND METHODS}

Study site. This study was conducted during the 1998/99 nesting season on the beaches of Ascension Island, South Atlantic ( $\left.7^{\circ} 57^{\prime} \mathrm{S}, 14^{\circ} 22^{\prime} \mathrm{W}\right)$. Although all nesting beaches were involved in the study, most data were collected from South West Bay (Beach 1), Long Beach (Beach 12), and North East Bay (Beach 27) (beach numbers as per Mortimer \& Carr (1987); our Fig. 1). These 3 beaches have been shown to hold approximately half of all nesting on the island (Beach 1: $10.7 \%$; Beach 12: 36.2\%; Beach 27: 9.7\%; Godley et al. 2001a), the remaining nests being recorded on another 22 beaches and coves.

Measurement of sand temperature at nest depth. Information on sand and nest temperatures was gathered using 'Tinytalk' data loggers (Orion Components Ltd, Chichester, UK) programmed to record synchronously at $4 \mathrm{~h}$ intervals. These data loggers were calibrated with a mercury thermometer of known accuracy (National Accreditation of Measurement and Sampling [NAMAS] certified to read $\pm 0.1^{\circ} \mathrm{C}$ of absolute temperature; Hays et al. 1999). Data loggers were placed in the sand from 8 December 1998 until 7 June 1999, in 3 randomly selected control sites (not nests) within the nesting zone on each of Beaches 1,12 and 27. Due to the risk of disturbance, as a result of the high density of nesting on these beaches, we protected the integrity study sites by hammering 4 stakes ( $>1 \mathrm{~m}$ long) into the sand at the corners of a $4 \mathrm{~m}^{2}$ area centred over the contol site. At least 30 to $50 \mathrm{~cm}$ of each stake was left above the surface of the sand. Loggers were placed at a depth of $77 \mathrm{~cm}$, the mean depth of green turtle nests on Ascension Island (Hays et al. 1993). Dataloggers took $<4 \mathrm{~h}$ to equilibrate with the surrounding sand, and thus initial readings within this period were not included in analyses. Loggers were retrieved and offloaded every 2 mo throughout the season and replaced with a different data logger, so as to reduce the chance of logger or data

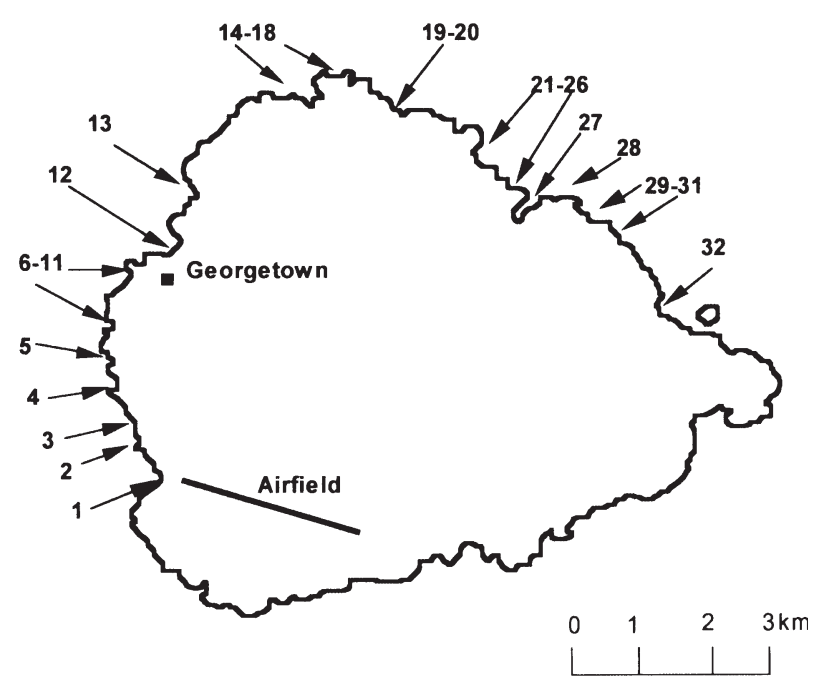

Fig. 1. Map of Ascension Island ( $7^{\circ} 57^{\prime} \mathrm{S}, 14^{\circ} 22^{\prime} \mathrm{W}$ ) illustrating beaches and coves numbered following scheme of Mortimer \& Carr (1987). Key to common names: (1) South West Bay; (2) Turtleshell; (3) Clarke's; (4) Payne Point; (5) Mitchell's Cove; (6) Blowhole; (7) POL South; (8) POL North; (9) Deadman's; (10) Fort Hayes; (11) Georgetown; (12) Long Beach; (13) Comfortless Cove; (14) English Bay (EB); (15) EB Cove 1; (16) EB Cove 2; (17) EB Cove 3; (18) EB Cove 4; (19) Ladies Loo West; (20) Ladies Loo East; (21) Porpoise Point (PP) Cove 1 ; (22) PP Cove 2; (23) PP Cove 3; (24) PP Cove 4; (25) PP Cove 5; (26) PP Cove 6; (27) Northeast Bay; (28) Beach Hut; (29) Hannay; (30) Pebbly West; (31) Pebbly East; (32) Spire. In addition, the major settlement, Georgetown, and the Airfield, where meteorological observations were made, are marked. As a result of their hosting negligible nesting, Beaches 13, 18, 19, 20 and 32 were not monitored 
loss. The temperature at minor beaches was measured at nest depth using electronic temperature probes with calibration traced to NAMAS standard. This was undertaken at 15 sites (1 per discrete minor beach and 2 at each of 4 clusters of beaches) on 4 occasions during the season in January, February, March and April. To minimise the added variation introduced by any seasonal thermal effect, each set of measurements was carried out within $72 \mathrm{~h}$ of the others.

Meteorological observations. To supplement control site data, meteorological observations (daily maximum and minimum air temperature) were obtained from the Royal Air Force Meteorological Office at the Ascension Island Airfield from 1 December 1998 to 31 October 1999.

Measurement of within-nest temperature. To monitor nest temperature, between 3 January and 4 June 1999, temperature loggers were placed in the centre of clutches of eggs as they were being laid ( $\mathrm{n}=13$ clutches for each of the 3 study beaches). We did not actively select nest sites, but placed data loggers amongst the eggs of the first laying female that we encountered each night. The logger was placed into the middle of the clutch of eggs during oviposition and the female was allowed to cover and camouflage the nest without disturbance. Data loggers measured $5 \times 5 \times 3 \mathrm{~cm}$ (volume: $75 \mathrm{~cm}^{3}$ ), representing some $1 \%$ of an average clutch as calculated conservatively by assessing the volume of eggs (mean clutch volume $=7278 \mathrm{~cm}^{3}$; mean no. of eggs per clutch $=127.5$; mean egg diameter $=$ $4.55 \mathrm{~cm}$; egg volume $={ }^{4} / 3 \pi \mathrm{r}^{3}$; Hays et al. 1993). After $45 \mathrm{~d}$, each nest was checked daily at dawn for signs of hatchling emergence. Once hatchling emergence was underway, nest contents were excavated, and data loggers and hatchlings collected. Incubation duration was calculated as the number of days between the night of laying and the night the first hatchlings emerged.

Collection of hatchlings for sexing. Ninety-six live hatchlings were collected from 21 nests and their sex was determined using standard histological techniques (Yntema \& Mrosovsky 1980, Miller \& Limpus 1981, Billett et al. 1992). Only live hatchlings were used, and when a large number of hatchlings were obtained, a random subsample was selected. For ethical reasons the number sampled was kept to a minimum.

\section{RESULTS}

\section{Control site temperatures}

The temperature at control sites on Beach 12 were taken as the calibration point for all others in the study as this was the single most important beach, hosting over $25 \%$ of the nests. Mean daily sand temperature at

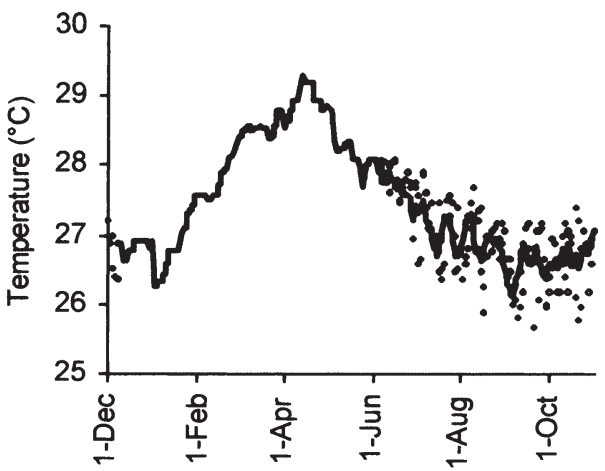

Fig. 2. Sand temperature at Beach 12 (1 December 1998 to 31 October 1999). From 8 December to 7 June, solid line denotes the mean 4-hourly temperature of 3 control sites measured by data loggers. From 1 to 8 December 1998 and 8 June to 31 October 1999, circles denote predicted sand temperature generated from air temperature using Eq. (1) (mean control site sand temperature on Beach $12=0.581 \times$ minimum daily temperature $+13.8^{\circ} \mathrm{C}, \mathrm{r}^{2}=0.76, F_{1,176}=585, \mathrm{p}<0.001$ ). Solid line from 8 June to 31 October is $7 \mathrm{~d}$ running mean of predicted sand temperature

control sites on Beach 12 was found to be closely related to both maximum daily air temperature and minimum daily air temperature, with the strongest relationships being with minimum daily air temperature (Fig. 2). This allowed us to predict sand temperature on Beach 12 for the periods when we were not able to monitor control site temperatures (1 to 7 December 1998 and 8 June to 31 October 1999) with a high degree of accuracy. These data were spliced with the actual control temperature data to give temperature at control depths for all days when clutches may have been incubating (Fig. 2). There was no regular diel variation in control site temperature.

\section{Nest temperatures}

Excluding 1 nest that was disturbed by the digging of another female, all the study nests hatched successfully. However, due to high winds or heavy seas destroying hatchling tracks, we were not always able to determine the exact date of the first hatchling emergence of some nests and these were excluded from our analyses $(n=7)$. Reliable hatchling emergence dates and temperature data were ascertained for 32 nests. Laying dates, incubation duration, and summary incubation temperature data are presented in Table 1. Mean temperature across the whole incubation duration ranged from 28.5 to $31.6^{\circ} \mathrm{C}$ (mean $=29.9^{\circ} \mathrm{C}$ ) on Beach 1, from 29.0 to $30.0^{\circ} \mathrm{C}$ (mean $=29.5^{\circ} \mathrm{C}$ ) on Beach 12 , and from 31.5 to $33.6^{\circ} \mathrm{C}$ (mean $=32.2^{\circ} \mathrm{C}$ ) on Beach 27 (Table 1). Temperature in the middle third of incubation ranged from 28.7 to $31.3^{\circ} \mathrm{C}$ (mean $=29.5^{\circ} \mathrm{C}$ ) on 
Table 1. Laying date (1999), incubation periods and temperature data for the 32 clutches in which temperature was monitored in 1999. ID:incubation duration; hatchlings sexed: F: female; M: male

\begin{tabular}{|c|c|c|c|c|c|c|c|c|c|c|c|c|c|}
\hline \multirow[t]{2}{*}{ Nest } & \multirow[t]{2}{*}{ Beach } & \multirow{2}{*}{$\begin{array}{l}\text { Laying } \\
\text { date }\end{array}$} & \multirow{2}{*}{$\begin{array}{l}\text { ID } \\
\text { (d) }\end{array}$} & \multicolumn{4}{|c|}{ Total ID } & \multicolumn{4}{|c|}{ Middle third ID } & \multicolumn{2}{|c|}{ Sexed $(n)$} \\
\hline & & & & Mean & $\mathrm{SD}$ & Min. & Max. & Mean & $\mathrm{SD}$ & Min. & Max. & $\mathrm{F}$ & M \\
\hline 1 & 1 & 4 Jan & 55 & 29.6 & 2.2 & 27.0 & 33.3 & 28.9 & 0.5 & 28.1 & 30.3 & - & - \\
\hline 2 & 1 & 19 Jan & 57 & 29.6 & 2.4 & 27.0 & 34.3 & 28.7 & 0.6 & 27.7 & 30.5 & - & - \\
\hline 3 & 1 & 2 Feb & 59 & 28.5 & 1.0 & 26.6 & 29.9 & 29.1 & 0.4 & 27.0 & 29.6 & - & - \\
\hline 4 & 1 & 9 Feb & 65 & 29.9 & 2.4 & 27.0 & 34.7 & 29.1 & 0.7 & 28.1 & 31.0 & 3 & 2 \\
\hline 5 & 1 & 9 Feb & 54 & 29.7 & 1.9 & 27.2 & 33.0 & 29.0 & 0.5 & 28.3 & 30.1 & 4 & 1 \\
\hline 6 & 1 & 9 Feb & 57 & 29.5 & 1.9 & 27.4 & 33.0 & 28.9 & 0.7 & 28.1 & 30.7 & - & - \\
\hline 7 & 1 & $4 \mathrm{Apr}$ & 54 & 30.1 & 1.2 & 28.8 & 32.2 & 29.6 & 0.7 & 29.2 & 30.7 & 3 & 0 \\
\hline 8 & 1 & $4 \mathrm{Apr}$ & 54 & 31.6 & 1.8 & 29.2 & 35.7 & 31.3 & 0.9 & 30.7 & 33.0 & 5 & 1 \\
\hline 9 & 1 & $5 \mathrm{Apr}$ & 51 & 31.4 & 1.5 & 29.2 & 34.9 & 30.9 & 0.8 & 30.3 & 32.2 & - & - \\
\hline 10 & 12 & 3 Jan & 59 & 29.1 & 2.5 & 26.6 & 33.7 & 28.1 & 0.6 & 27.0 & 29.6 & 2 & 4 \\
\hline 11 & 12 & 4 Jan & 58 & 29.9 & 2.4 & 27.4 & 34.1 & 29.0 & 0.8 & 27.7 & 31.1 & 2 & 2 \\
\hline 12 & 12 & 4 Feb & 56 & 29.5 & 1.6 & 27.7 & 32.2 & 29.0 & 0.6 & 28.1 & 30.7 & - & - \\
\hline 13 & 12 & 4 Feb & 61 & 29.0 & 2.0 & 25.9 & 32.6 & 28.5 & 0.5 & 27.7 & 29.9 & - & - \\
\hline 14 & 12 & 4 Feb & 64 & 29.5 & 2.2 & 26.8 & 33.3 & 29.1 & 1.0 & 27.9 & 31.4 & 3 & 2 \\
\hline 15 & 12 & 4 Feb & 63 & 29.1 & 1.8 & 27.1 & 32.1 & 28.7 & 0.7 & 27.8 & 30.3 & 1 & 8 \\
\hline 16 & 12 & 4 Feb & 57 & 29.8 & 2.3 & 27.0 & 34.5 & 29.1 & 0.7 & 28.1 & 31.1 & 2 & 5 \\
\hline 17 & 12 & 9 Feb & 60 & 29.6 & 1.7 & 27.0 & 33.0 & 29.2 & 0.6 & 28.5 & 30.5 & 6 & 0 \\
\hline 18 & 12 & $5 \mathrm{Apr}$ & 56 & 30.0 & 1.3 & 28.4 & 32.2 & 29.6 & 0.8 & 28.8 & 31.1 & - & - \\
\hline 19 & 12 & $5 \mathrm{Apr}$ & 60 & 29.3 & 0.9 & 28.1 & 31.1 & 29.3 & 0.7 & 28.8 & 30.3 & - & - \\
\hline 20 & 12 & $5 \mathrm{Apr}$ & 55 & 29.7 & 1.3 & 27.4 & 31.4 & 29.3 & 0.9 & 27.4 & 30.7 & 7 & 0 \\
\hline 21 & 27 & 5 Jan & 56 & 32.4 & 2.3 & 28.8 & 35.7 & 32.6 & 1.5 & 30.3 & 35.3 & 3 & 0 \\
\hline 22 & 27 & 5 Jan & 53 & 31.5 & 2.0 & 29.2 & 34.5 & 31.1 & 1.0 & 29.3 & 33.3 & 3 & 0 \\
\hline 23 & 27 & 8 Feb & 54 & 31.5 & 1.8 & 28.8 & 35.0 & 31.3 & 0.9 & 30.2 & 33.2 & 4 & 0 \\
\hline 24 & 27 & $8 \mathrm{Feb}$ & 51 & 31.8 & 2.1 & 29.2 & 34.9 & 31.3 & 1.2 & 29.9 & 33.7 & 3 & 0 \\
\hline 25 & 27 & $8 \mathrm{Feb}$ & 48 & 32.3 & 1.9 & 29.2 & 35.7 & 31.9 & 0.9 & 31.1 & 33.7 & 5 & 0 \\
\hline 26 & 27 & $10 \mathrm{Feb}$ & 63 & 31.9 & 0.9 & 29.9 & 33.0 & 32.5 & 0.6 & 31.4 & 33.0 & 3 & 0 \\
\hline 27 & 27 & $10 \mathrm{Feb}$ & 55 & 32.7 & 2.5 & 28.4 & 36.5 & 33.1 & 1.4 & 31.1 & 35.3 & 3 & 0 \\
\hline 28 & 27 & $10 \mathrm{Feb}$ & 53 & 31.8 & 1.8 & 29.6 & 34.9 & 31.6 & 0.9 & 30.3 & 33.3 & - & - \\
\hline 29 & 27 & 7 Apr & 48 & 32.5 & 0.3 & 31.1 & 33.3 & 32.5 & 0.2 & 32.2 & 32.6 & 3 & 0 \\
\hline 30 & 27 & 7 Apr & 54 & 32.5 & 0.6 & 30.3 & 34.1 & 32.5 & 0.3 & 32.2 & 33.0 & 3 & 0 \\
\hline 31 & 27 & $8 \mathrm{Apr}$ & 50 & 32.0 & 0.6 & 30.7 & 33.3 & 31.9 & 0.3 & 31.5 & 32.6 & - & - \\
\hline 32 & 27 & $8 \mathrm{Apr}$ & 48 & 33.6 & 1.9 & 30.7 & 36.5 & 33.5 & 1.1 & 32.2 & 35.7 & 3 & 0 \\
\hline
\end{tabular}

Beach $1,28.1$ to $29.6^{\circ} \mathrm{C}\left(\right.$ mean $\left.=28.9^{\circ} \mathrm{C}\right)$ on Beach 12 and 31.0 to $33.5^{\circ} \mathrm{C}$ (mean $=32.1^{\circ} \mathrm{C}$ ) on Beach 27 (Table 1). There was no regular diel temperature variation in any of the nests.

\section{Nest temperature and sex ratio}

The number of hatchlings subject to sexing and the resultant sex ratio are given in Table 1. Using maximum likelihood analysis (Girondot 1999), an estimated pivotal temperature of $28.8^{\circ} \mathrm{C}$ for this population was the result ( $\mathrm{SD} 0.17$; likelihood $=3.4 \times 10^{-9}$; Fig. 3 ). The equation to describe these results is

$$
\text { Proportion female }=\frac{1.0}{1+\exp \left(\frac{-(T-28.8)}{0.6}\right)}
$$

where $T=$ mean temperature in the middle third of incubation. In addition, for comparison, data from other published studies are shown in Fig. 3.

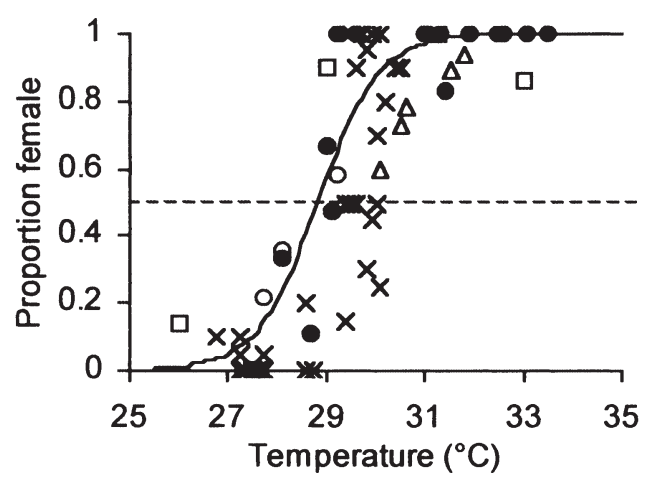

Fig. 3. Relationship between temperature in the middle third of incubation and the sex ratio (proportion females) of hatchling green turtles. ( ) Data from this study (Table $1 ; \mathrm{n}=15$; note all clutches of equivalent temperature were grouped); (-) relationship derived from maximum likelihood analysis of Ascension Island data (Eq. 2). Additional data presented are from: Miller \& Limpus (1981) $(\square ; \mathrm{n}=3)$; Mrosovsky et al. (1984) $(O ; \mathrm{n}=3)$; Standora \& Spotila (1985) $\left(\times_{i} \mathrm{n}=33\right) ;$ Kaska et al. (1998) $\left(\Delta_{i} \mathrm{n}=5\right)$. Broken line denotes equal sex ratio 
Table 2. Relative magnitude of nesting (total number of nests and proportion of total) on each of the beaches and beach clusters on Ascension Island during the 1998/99 season (after Godley et al. 2001a), with the mean difference in temperature from Beach $12\left(\delta \mathrm{T},{ }^{\circ} \mathrm{C}\right)$ and the resultant estimated sex ratio for each beach for the whole season

\begin{tabular}{|crrrc|}
\hline $\begin{array}{c}\text { Beach no. } \\
(\mathrm{s})\end{array}$ & $\begin{array}{c}\text { Number } \\
\text { of nests }\end{array}$ & $\begin{array}{c}\text { Proportion } \\
\text { nesting }(\%)\end{array}$ & $\begin{array}{c}\delta \mathrm{T} \\
\left({ }^{\circ} \mathrm{C}\right)\end{array}$ & $\begin{array}{c}\text { Sex ratio } \\
(\% \text { female })\end{array}$ \\
\hline 1 & 1485 & 10.7 & 0.1 & 77.5 \\
2 & 446 & 3.2 & -0.4 & 61.3 \\
3 & 564 & 4.1 & 0.3 & 81.4 \\
4 & 330 & 2.4 & 0.0 & 73.8 \\
5 & 258 & 1.9 & -0.6 & 57.8 \\
$6-11$ & 1566 & 11.3 & -0.4 & 61.3 \\
12 & 5019 & 36.2 & 0.0 & 73.8 \\
$14-17$ & 942 & 6.8 & -0.6 & 54.2 \\
$21-25$ & 641 & 4.6 & -0.4 & 61.3 \\
26 & 15 & 0.1 & 0.7 & 88.8 \\
27 & 1351 & 9.7 & 2.7 & 99.4 \\
28 & 363 & 2.6 & 1.6 & 96.9 \\
29 & 636 & 4.6 & 0.7 & 88.8 \\
$30-31$ & 264 & 1.9 & 2.9 & 99.6 \\
\hline
\end{tabular}

\section{Among-beach variation in sand temperature}

Inter-beach variation in sand temperature has previously been attributed to sand colour or albedo on Ascension Island (Hays et al. 2001a). Table 2 shows the relative importance of the different beaches and the mean difference in control site temperature versus mean temperature of Beach 12. The seasonal pattern of temperature has been shown to vary consistently among beaches (Hays et al. 1999); therefore, to generate seasonal profiles in temperature for all nesting beaches, the mean difference with coincidental temperature on Beach 12 for each site was subtracted from the temperature profile for Beach 12.

\section{Modelling the seasonal profile in hatchling sex ratio}

Using the data from this study we can develop a protocol for the whole colony at Ascension Island for an entire season:

(1) Establish the pivotal temperature for the population, which we have accomplished in this study.

(2) Describe the seasonal temperature at control site depths. We have done this for the major beaches in previous seasons (Hays et al. 1999), and during this study we have gathered data to allow the pattern to be modelled for all beaches.

(3) Quantify the level of metabolic heating by developing embryos during the middle third of incubation. This was accomplished by Broderick et al. (2001), with the mean amount of metabolic heating during the middle third of incubation being $1.05^{\circ} \mathrm{C}$.
(4) Through a combination of points (2) and (3) it is then possible to model the temperature of all nests during the middle third of incubation, regardless of date or location of nesting. For each clutch it was assumed that the middle third temperature would be sufficiently described by calculating the mean temperature from Day 19 to Day 37 of incubation, which is the middle third of incubation time for clutches with a median incubation duration of $55 \mathrm{~d}$.

(5) Using the established relationship between mean temperature in the middle third of incubation and the subsequent sex ratio of hatchlings described here, it is then possible to model the expected temperature and thus sex ratio of any clutch regardless of its date or location nesting.

(6) Given the temporal distribution of nesting (Godley et al. 2001a, and Fig. 4a), it is then possible to estimate the sex ratio of hatchling production for each beach (Table 2). Our estimates of hatchling sex ratio vary from $54 \%$ female for the very light coloured beaches (14 to 17 ), to $>99 \%$ female on the very dark beaches $(27,30$ and 31$)$.
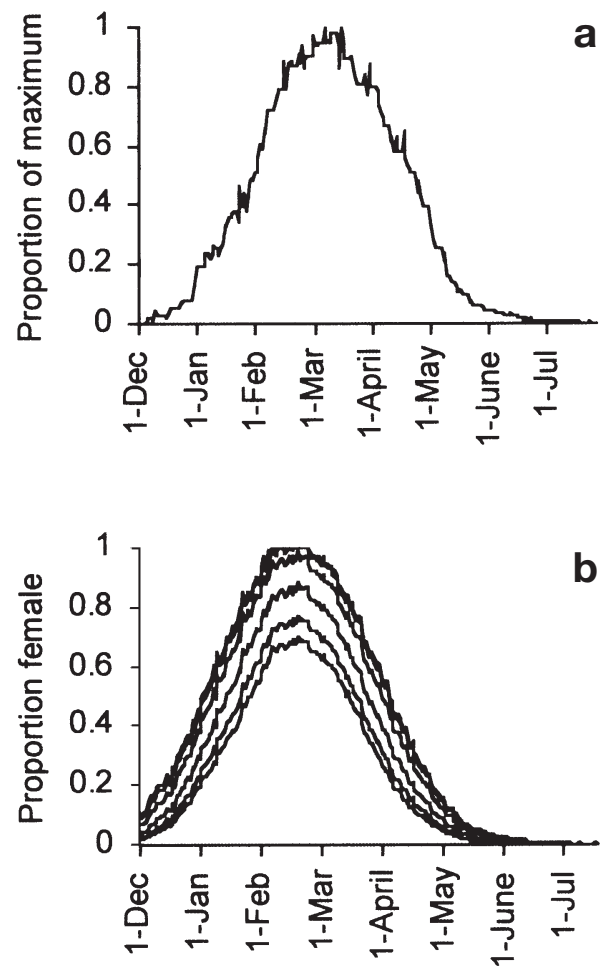

Fig. 4. Seasonal profiles (1 December 1998 to 15 July 1999) of: (a) the proportion of clutches laid throughout Ascension Island on each day scaled to a maximum of 1 (after Godley et al. 2001a); (b) the modelled sex ratio (proportion females) of hatchlings from a hypothetical turtle laying 4 clutches at each of 14 sites depending on the day the first clutch was laid. A separate line is shown for each beach or beach cluster monitored (Table 2, Fig. 1) 
(7) Given the magnitude of nesting on each of the beaches (Table 2), it is then possible to estimate the overall sex ratio of hatchlings as $75 \%$ female for the whole colony for the season of study, a female:male ratio of 3:1.

\section{Impact on reproductive output of individuals}

There is marked seasonality in the magnitude of nesting (Fig. 4a). This, coupled with the seasonal cycle of temperature (Fig. 2), will make the sex ratio of progeny differ among females nesting at different times of what is shown to be a lengthy season. On Ascension Island, each female is thought to lay, on average, between 3 and 4 clutches per season, with a modal internesting interval of $13 \mathrm{~d}$ (Mortimer \& Carr 1987). If, for each of the 14 study sites, we model the likely sex ratio of hatchlings from 4 clutches of eggs, laid by females nesting at $13 \mathrm{~d}$ intervals, the sex ratio would show a marked seasonal pattern depending on when the first clutch was laid and the nesting site (Fig. 4b).

\section{Incubation duration, air temperature, and sand temperature in the prediction of sex ratio}

In the generation of our estimate of hatchling sex ratio, we have used a combination of both air temperature and control site sand temperature to predict nest temperatures, and thus sex ratios, for the whole season. Quality of performance of these methods is worthy of consideration. For all 32 nests in which the sand temperature was known (Table 1 ; mean temperature in middle third of incubation $\pm \mathrm{SD}: 30.3 \pm 1.6^{\circ} \mathrm{C}$, range 28.1 to $33.5^{\circ} \mathrm{C}$ ), we estimated the sand temperature in the middle third of incubation by:

(1) Calculating predicted control site temperature on that beach during the middle third of incubation and then adding $1.05^{\circ} \mathrm{C}$ to account for metabolic heating (estimated mean temperature in middle third of incubation $\pm \mathrm{SD}: 30.4 \pm 1.4^{\circ} \mathrm{C}$, range 29.7 to $30.4^{\circ} \mathrm{C}$ ) .

(2) Estimating control site temperature on Beach 12 during the middle third of incubation from minimum air temperature (Eq. 1), and then adding the beachspecific correction (Table 2) and $1.05^{\circ} \mathrm{C}$ to account for metabolic heating (estimated mean temperature in middle third of incubation $\pm \mathrm{SD}: 30.3 \pm 1.4^{\circ} \mathrm{C}$, range 29.4 to $30.2^{\circ} \mathrm{C}$ ).

There was no significant difference among the means of these 2 estimates or the actual mean temperature in the middle third of incubation (ANOVA, $F_{2,93}=0.07$, $\mathrm{p}=0.93$ ), and there was no difference in the mean estimated sex ratio derived from these 3 data sets when calculated using Eq. (2) (ANOVA, $\left.F_{2,93}=0.6, p=0.54\right)$.
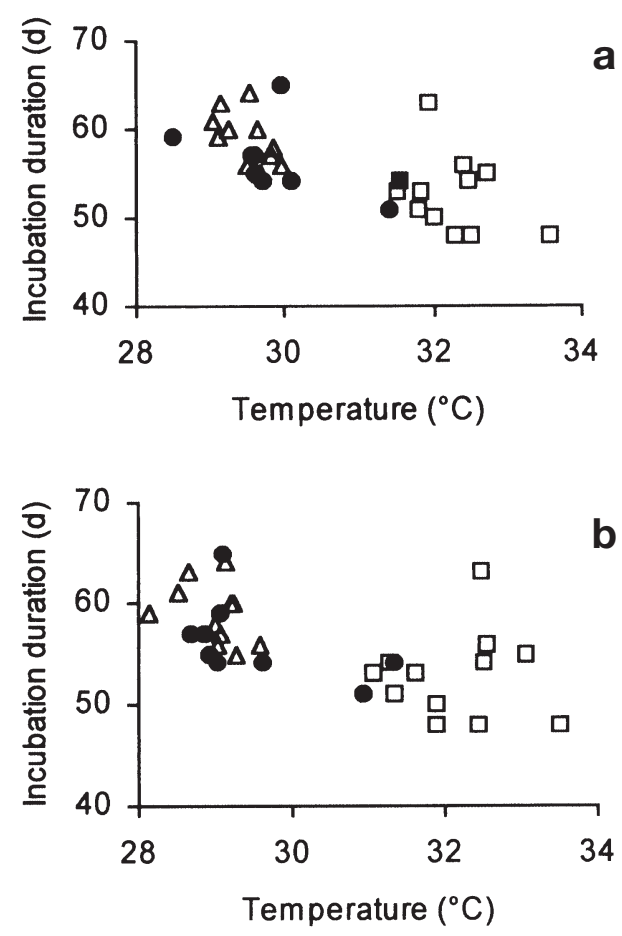

Fig. 5. Mean incubation temperature and incubation duration (ID): (a) throughout ID; (b) during the middle third of ID. Location of study nests: $(\Delta)$ Beach 1, ( ) Beach 12, (ㅁ) Beach 27

Incubation duration was found to be closely related to both temperature throughout incubation (Eq. 3: Incubation duration [ID] in days $=-2.18 \times$ mean temperature throughout incubation $+123 ; \mathrm{r}^{2}=0.45, F_{1,30}=24, \mathrm{p}<$ 0.001; Fig. 5a), and temperature in the middle third of incubation (Eq. 4: ID $=-1.67 \times$ mean temperature in middle third of incubation $(T)+107 ; \mathrm{r}^{2}=0.35, F_{1,30}=16$,

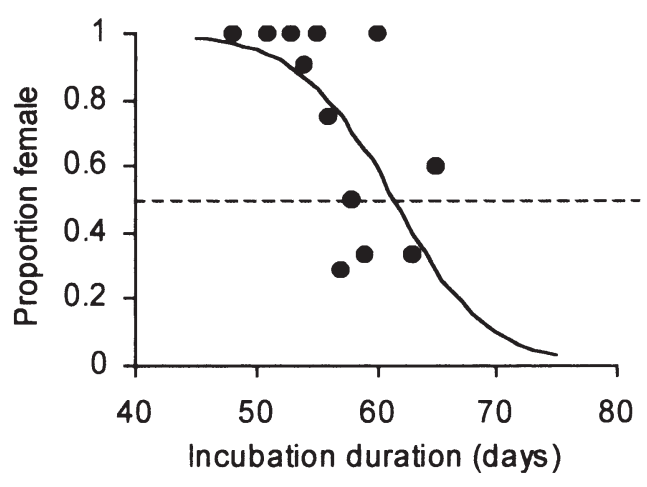

Fig. 6. The relationship between incubation duration (ID in days) and the sex ratio (proportion females) of hatchling green turtles. (), data from this study (Table 1) and the solid line is the relationship derived from maximum likelihood analysis of these data (Eq. 5) 
$p<0.001$; Fig. 5b). These data confirm incubation duration may be used as a proxy for nest temperature. When incubation duration was entered into the maximum likelihood analysis as a predictor of hatchling sex ratio, an estimate of a pivotal duration of $61.4 \mathrm{~d}$ resulted (SD 1.0; likelihood $=1.4 \times 10^{-9} ;$ Fig. 6 ). The equation describing the results from this analysis is

$$
\text { Proportion female }=\frac{1.0}{1+\exp \left(\frac{-(\mathrm{ID}-61.4)}{3.9}\right)}
$$

where ID = incubation duration (d).

\section{DISCUSSION}

Previous studies have tended to establish the pivotal temperature by collecting eggs from beaches and then incubating them in constant conditions of temperature and light in the laboratory (Marcovaldi et al. 1997, Godfrey et al. 1999). Such an approach is particularly pragmatic for smaller species, where nests are shallow and may have a complicated thermal environment including marked diel fluctuations in temperature (Georges et al. 1994, Hanson et al. 1998, Kaska et al. 1998). However, green turtles at Ascension Island are large and lay deep nests which, consequently, have no regular diel thermal fluctuations, and hence the thermal environment tends to lack marked short-term changes (cf. Broderick et al. 2000, Booth \& Astill 2001). Our results conclusively show that the thermal environment within nests at Ascension Island can be strongly related to the incubation temperature and produce a pivotal temperature $\left(28.8^{\circ} \mathrm{C}\right)$ very close to those reported elsewhere (Miller \& Limpus 1981, Standora \& Spotila 1985, Spotila et al. 1987, Godfrey 1997, Kaska et al. 1998, Palaniappan 1998, Broderick et al. 2000). When the available data from all of these other studies is viewed in conjunction with our data (Fig. 3), it can be seen that, although interpopulation differences in the mechanism of TSD may exist (Chevalier et al. 1999), the trait is relatively conservative in this species, with among-population variance approximating that of the data in our study at Ascension Island.

Our estimate of the overall sex ratio of hatchling production at Ascension Island as $75 \%$ female is similar to the $67 \%$ at Tortuguero, Costa Rica (Standora \& Spotila 1985, Spotila et al. 1987) $68 \%$ (note that this is a $14 \mathrm{yr}$ average; interannual range: 20 to $90 \%$ ) at Suriname (Godfrey et al. 1996) and the $52.9 \%$ (shaded) to $85.4 \%$ (open beach) in Malaysia (Palaniappan et al. 2000). These all contrast markedly with the studies of Mediterranean green turtles (Broderick et al. 2000, Casale et al. 2000), which have suggested sex ratios extremely skewed towards females. It would appear that overall, although hatchling sex ratios in Atlantic populations of this species may be generally skewed towards females, this is not to the same level as the loggerhead turtles in the region (Mrosovsky \& Provancha 1989, 1992, Marcovaldi et al. 1997, Godley et al. 2001b).

This study has allowed us to compare methodologies for estimating sex ratios of hatchling production. When calibrated with nest temperature, both air temperature and sand temperature at nest depth have utility in allowing the prediction of nest temperature and thus sex ratio. There was a closer relationship between mean temperature for the whole incubation duration and incubation duration than between mean temperature during the middle third of incubation and incubation duration. A similar difference was found in green turtles in Northern Cyprus (Broderick et al. 2000), and it was attributed to the fact that incubation duration is an integration of developmental rates throughout incubation and more likely to be dictated by the thermal regimes throughout the period. However, in the Ascension sample, much less variation is explained by this relationship, suggesting that further investigation of this aspect would be necessary before incubation duration could be used to estimate seasonal patterns in sex ratio of hatchling production in this population. If nests incubate at different temperatures at different parts of their incubation as a result of seasonal changes in sand temperatures, variance can be introduced which would detract from the utility of this technique when compared with intranest temperature logging or using carefully calibrated air or sand temperature data.

By measuring nest temperature using only 1 logger in the middle of the clutch, intranest temperature differences may be overlooked. We have limited data (6 clutches in which data loggers were placed at the top, middle and bottom of the clutch; authors' unpubl. data) showing that within-nest differences are not great (mean $0.45^{\circ} \mathrm{C}$, range 0.1 to $0.9^{\circ} \mathrm{C}$ ), and temperature loggers placed in the middle of the clutch are therefore representative of the temperature of the vast majority of eggs. Similar findings were found by Booth \& Astill (2001). The strengths of such an approach are that it incorporates variation resultant from inter-nest differences in depth, moisture and seasonal cycles in sand temperature. This methodology is also important because it involves a relatively large sample of clutches from different individuals and incorporates possible among-individual genetic differences in the mechanisms of TSD, a factor which laboratory incubation of eggs from a few clutches cannot account for.

The possibility of interannual variability, in both the seasonality of breeding and meteorological factors, as introducing variability in sex ratios of hatchling production is one which has been previously highlighted as a source of error in similar studies (Mrosovsky et al. 
1984, Godfrey et al. 1996). It is likely that the 1998/99 nesting season was not atypical in this respect, as seasonal thermal patterns have been shown to be markedly consistent (Hays et al. 1999) and the seasonality and spatial distribution of nesting appear to be highly similar among seasons (Mortimer \& Carr 1987, Godley et al. 2001a), factors which are likely to result in similar sex ratios in different years. When undertaking a simple modelling approach, such as the one carried out here, we make several assumptions, which, although they are not likely to greatly bias our results, are worthy of mention. We assumed that on average the number of eggs in a clutch, the proportion of nests producing hatchlings and the proportion of eggs hatching did not vary systematically during the season.

If the suggested female-skewed primary sex ratios continue to adulthood, a female-biased operational sex ratio would result. In this situation, if natal philopatry for both sexes is in operation, it might be a concern that there would be too few males to allow successful fertilisation of available females. There is no evidence to suggest an infertility problem leading to low hatching. Therefore, it would appear that the sex ratios produced are either balanced or adequate. The bias in sex ratio could be lowered by differentially higher mortality of smaller, less fit turtles (mostly females) from very warm, quickly developing nests as has been suggested in other groups (O'Steen 1998, Packard et al. 1999, Rhen \& Lang 1999). In addition, even if sex ratios are not balanced, there are several mechanisms which could act in concert to allow any bias to persist without a detrimental effect on fertility. First, males can mate with a number of females in a breeding season where extended residence of several weeks at the courting grounds has been demonstrated (Limpus 1993, Hays et al. 2001b). Secondly, it has been suggested that males may undertake breeding remigrations with a greater frequency than females from the same population (Limpus 1993, Pandav et al. 2000).

Regardless of how the skewed sex ratios at Ascension Island and other conspecific nesting colonies in the Atlantic are balanced or maintained, given the temporal and spatial variability in hatchling sex ratios demonstrated at Ascension Island, the timing and location of nesting can have profound effects on the resultant hatchling sex ratio and therefore the fitness of the mother. Only females who commence laying very early or very late in the season will produce male-biased offspring. Given the seasonal distribution of nesting, peaking in March, with the highest air and sand temperatures, this is likely to be a very small proportion of the population. However, on average, most females will produce offspring of both sexes.

In conclusion, with this study we have demonstrated how we can reliably generate the sex ratio of hatchling production from a whole colony for a single season.
This methodology could be used at other colonies, and it will now be possible to reconstruct historical hatchling sex ratios for this population. If these are relatively consistent then it is not difficult to imagine how factors such as differential mortality of hatchlings, multiple mating and variable remigration rates could account for such biases leading to a balanced or at least an adequate operational sex ratio.

Acknowledgements. This work was funded by grants from the Darwin Initiative for the Survival of the Species, the UK Department of Environment, Trade and Regions (DETR), The Foreign and Commonwealth Office Fund for the Environment in the Overseas Territories, and the Natural Environment Research Council (NERC). Work was carried out in conjunction with the Ascension Island Administrators, HH Roger Huxley and HH Geoffrey Fairhurst. The success of fieldwork would not have been possible without the efforts of Darwin Initiative Turtle Wardens and the many volunteers on Ascension Island. We are grateful for the additional logistical support of Ascension Island Services, Cable and Wireless, Computer Services Raytheon, First Ascension Scout Group, Johnny Hobson, Merlin Communications Ltd, Dave Rayney, Reed Family, The Royal Air Force and the United States Air Force. Darren Clark, Matthew Godfrey and Marc Girondot assisted with data analyses. Matthew Godfrey and Andrew Kelly gave constructive comments on a previous version and the manuscript was improved by the input of 3 anonymous reviewers.

\section{LITERATURE CITED}

Ackerman RA (1997) The nest environment and the embryonic development of sea turtles. In: Lutz PL, Musick JA (eds) The biology of sea turtles. CRC Press, Boca Raton, p 83-106

Billett FS, Collins P, Goulding DA, Sutherland J (1992) The development of Caretta caretta at $25-34^{\circ} \mathrm{C}$ in artificial nests. J Morph 213:251-263

Binckley CA, Spotila JR, Wilson KS, Paladino FV (1998) Sex determination and sex ratios of Pacific leatherback turtles Dermochelys coriacea. Copeia 1998:291-300

Booth DT, Astill K (2001) Temperature variation within and between nests of the green sea turtle Chelonia mydas (Chelonia: chelonidae) on Heron Island, Great Barrier reef. Aust J Zool 49:71-84.

Broderick AC, Godley BJ, Reece S, Downie JR (2000) Incubation periods and sex ratios of green turtles: highly female biased hatchling production in the eastern Mediterranean. Mar Ecol Prog Ser 202:273-281

Broderick AC, Godley BJ, Hays GC (2001) Metabolic heating and the prediction of sex ratios for green turtles (Chelonia mydas). Physiol Biochem Zool 74:161-170

Carrasco AM, Marquez MR, Benitez VV, Diaz FJ, Jimenez QC (2000) The effect of temperature change on the sex ratio of Kemp's ridley nests in the hatchery center at Rancho Nuevo, Tamaulipas, Mexico. In: Kalb HJ, Wibbels T (Compilers) Proc 19th Ann Symp Sea Turtle Biol Conserv. NOAA Tech Memo, NMFS-SEFSC-443, p 128-129

Casale P, Gerosa G, Yerli SV (2000) Female-biased primary sex ratio of the green turtle, Chelonia mydas, estimated through sand temperatures at Akyatan, Turkey. Zool Middle East 20:33-42 
Chevalier J, Godfrey MH, Girondot M (1999) Significant difference of temperature-dependent sex determination between French Guiana (Atlantic) and Playa Grande (CostaRica, Pacific) Leatherbacks (Dermochelys coriacea). Ann Sci Nat Zool Biol Anim 20:147-152

Georges A, Limpus C, Stoutjesdijk R (1994) Hatchling sex ratio in the marine turtle Caretta caretta is determined by proportion of development at a temperature, not daily duration of exposure. J Exp Zool 270:432-443

Girondot M (1999) Statistical description of temperaturedependent sex determination using maximum likelihood. Evol Ecol Res 1:479-486

Godfrey MH (1997) Sex ratios of sea turtle hatchlings: direct and indirect estimates. $\mathrm{PhD}$ thesis, University of Toronto

Godfrey MH, Barreto R, Mrosovsky N (1996) Estimating past and present sex ratios of sea turtles in Suriname. Can J Zool 74:267-277

Godfrey $\mathrm{MH}, \mathrm{D}^{\prime}$ Amato AF, Marcovaldi MA, Mrosovsky N (1999) Pivotal temperature and predicted sex ratios for hatchling hawksbill turtles from Brazil. Can J Zool 77: 1465-1473

Godley BJ, Broderick AC, Hays GC (2001a) Nesting of green turtles Chelonia mydas at Ascension Island, South Atlantic. Biol Conserv 97:151-158

Godley BJ, Broderick AC, Mrosovsky N (2001b) Estimating hatchling sex ratios of loggerhead turtles in Cyprus from incubation durations. Mar Ecol Prog Ser 210:195-201

Hanson J, Wibbels T, Martin RE (1998) Predicted female bias in sex ratios of hatchling loggerhead sea turtles from a Florida nesting beach. Can J Zool 76:1850-1861

Hays GC, Adams CR, Speakman JR (1993) Reproductive investment of green turtles nesting on Ascension Island. Can J Zool 7:1098-1103

Hays GC, Adams CR, Mortimer JA, Speakman JR (1995) Inter- and Intra- beach thermal variation for green turtle nests on Ascension Island, South Atlantic. J Mar Biol Assoc UK 75:405-411

Hays GC, Godley BJ, Broderick AC (1999) Long-term thermal conditions on the nesting beaches of green turtles on Ascension Island. Mar Ecol Prog Ser 185:297-299

Hays GC, Ashworth JS, Barnsley MJ, Broderick AC, Emery DR, Godley BJ, Henwood A, Jones EL (2001a) The importance of sand albedo for the thermal conditions on sea turtle nesting beaches. Oikos 93:87-95

Hays GC, Godley BJ, Broderick AC, Glen F, Nicholls WJ (2001b) The movements and submergence behaviour of male green turtles at Ascension Island. Mar Biol 139:395-399

Hewavisenthi D, Parmenter CJ (2000) Hydric environment and sex determination in the flatback turtle (Natator depressus Garman) (Chelonia:Chelonidae). Aust J Zool 48: 653-659

Janzen FJ, Paukstis GL (1991) Environmental sex determination in reptiles: ecology, evolution and experimental design. Q Rev Biol 66:149-179

Kaska Y, Downie JR, Tippett R, Furness R (1998) Natural temperature regimes for loggerhead and green turtle nests in the eastern Mediterranean. Can J Zool 76:723-729

Limpus CJ (1993) The green turtle Chelonia mydas in Queensland-breeding males in the southern Great Barrier Reef. Wildl Res 20:513-525

Maloney JE, Darian-Smith C, Takahashi Y, Limpus CJ (1990) The environment for development of the embryonic loggerhead turtle (Caretta caretta) in Queensland. Copeia 1990:378-387

Marcovaldi MA, Godfrey MH, Mrosovsky N (1997) Estimating sex ratios of loggerhead turtles in Brazil from pivotal incubation durations. Can J Zool 75:755-770
Maxwell JA, Motara AA, Frank GH (1988) A micro-environmental environmental study of the effect of temperature on the sex ratios of the loggerhead turtle, Caretta caretta, from Tongaland, Natal. S Afr J Zool 23:342-350

McCoy CJ, Vogt RC, Censky RJ (1983) Temperature controlled sex determination in the sea turtle Lepidochelys olivacea. J Herpetol 17:404-406

Miller JD, Limpus CJ (1981) Incubation period and sexual differentiation in the green turtle Chelonia mydas L. In: Banks C, Martin A (eds) Proceedings of the Melbourne herpetological symposium zoological board of Victoria, 1981. Zoological Board of Victoria, Parkville, p 66-73

Morreale SJ, Ruiz GJ, Spotila JR, Standora EA (1982) Temperature-dependent sex determination: current practices threaten conservation of sea turtles. Science 216: 1245-1247

Mortimer JA, Carr A (1987) Reproduction and migrations of the Ascension Island green turtle (Chelonia mydas). Copeia 1987:103-113

Mrosovsky N (1994) Sex ratios of sea turtles. J Exp Zool 270: $16-27$

Mrosovsky N (1988) Pivotal temperatures for loggerhead turtles (Caretta caretta) from northern and southern nesting beaches. Can J Zool 66:661-669

Mrosovsky N, Pieau C (1991) Transitional range of temperature, pivotal temperatures and thermosensitive stages for sex determination in reptiles. Amphib-Reptilia 12: 169-179

Mrosovsky N, Provancha J (1989) Sex ratio of loggerhead sea turtles on a Florida beach. Can J Zool 67:2533-2539

Mrosovsky N, Provancha J (1992) Sex ratio of hatchling loggerhead sea turtles: data and estimates from a 5-year study. Can J Zool 70:530-538

Mrosovsky N, Dutton PH, Whitmore CP (1984) Sex ratios of two species of sea turtle nesting in Suriname. Can J Zool 62:2227-2239

Mrosovsky N, Bass A, Corliss LA, Richardson JI, Richardson TH (1992) Pivotal and beach temperatures for the hawksbill turtles nesting in Antigua. Can J Zool 70: 1920-1925

O'Steen S (1998) Embryonic temperature influences juvenile temperature choice and growth in snapping turtles Chelydra serpentina. J Exp Biol 201:439-449.

Packard G, Miller K, Packard MJ, Birchard GF (1999) Environmentally induced variation in body size and condition in hatchling snapping turtles (Chelydra serpentina). Can J Zool 77:278-289

Palanniappan P (1998) Temperature profiling and sex ratios of green turtle hatchlings (Chelonia mydas) of Chagar Hutang Beach in Pulau Redang, Terrenggany, Malaysia. MSc thesis, University Putra Malaysia Terrengganu

Palaniappan P, Chan EH, Liew LC (2000) Spatial and temporal changes in sex ratios of green turtle (Chelonia mydas) hatchlings in Pulau Redang, Malaysia. In: Kalb H, Wibbels $\mathrm{T}$ (eds) Proc 19th Ann Symp Sea Turtle Conserv Biol. NOAA Tech Memo, NMFS-SEFSC-443, p 233-235

Pandav B, Bunugopan K, Sutari D, Choudhury BC (2000) Fidelity of male olive ridley sea turtles to a breeding ground. Mar Turtle News 87:9-10.

Rhen T, Lang JW (1999) Incubation temperature and sex affect mass and energy reserves of hatchling sapping turtles, Chelydra serpentina. Oikos 86:311-319

Rimbolt-Baly F, Lescure J, Frete J, Pieu C (1986) Sensibilité à la température de la différenciation sexuelle chez tortue Luth Dermochelys coriacea (Vandelli 1761); application des données de l'incubation artificielle à l'étude de la sexratio dans la nature. Ann Sci Nat Zool 13:277-290 
Spotila JR, Standora EA, Morreale SJ, Ruiz GJ (1987) Temperature dependent sex determination in the green turtle (Chelonia mydas): effects on the sex ratio on a natural beach. Herpetologia 43:74-81

Standora EA, Spotila JR (1985) Temperature dependent sex determination in sea turtles. Copeia 1985:480-482

Wibbels T, Rostal DC, Byles R (1998) High pivotal temperature in the sex determination of the olive ridley turtle

Editorial responsibility: Otto Kinne (Editor),

Oldendorf/Luhe, Germany
Lepidochelys olivacea from Playa Nancite, Costa Rica. Copeia 1998:1086-1088

Wibbels T, Hillis-Star ZM, Phillips B (1999) Female biased sex ratios of hatchlings hawksbill sea turtles from a Caribbean nesting beach. J Herpetol 33:142-144

Yntema CL, Mrosovsky N (1980) Sexual differentiation in hatchling loggerheads (Caretta caretta) incubated at different controlled temperatures. Herpetologia 36:33-36

Submitted: April 6, 2001, Accepted: July 12, 2001

Proofs received from author(s): January 15, 2002 